Post-print of: Plant Foods Hum. Nutr. 70. 42-49 (2015)

\title{
Obtaining from Grape Pomace an Enzymatic Extract with Anti-inflammatory Properties
}

\author{
B. Rodríguez-Morgado • M. Candiracci • \\ C. Santa-María $\cdot$ E. Revilla • B. Gordillo • \\ J. Parrado • A. Castaño
}

\begin{abstract}
Grape pomace, a winemaking industry by-product, is a rich source of bioactive dietary compounds. Using proteases we have developed an enzymatic process for obtaining a water-soluble extract (GP-EE) that contains biomolecules such as peptides, carbohydrates, lipids and polyphenols in soluble form. Of especial interest is its high polyphenol content $(12 \%)$, of which $77 \%$ are flavonoids and $33 \%$ are phenolic acids. The present study evaluates in vitro the potential anti-inflammatory effect of GP-EE by monitoring the expression of inflammatory molecules on N13 microglia cells stimulated with lipopolysaccharide (LPS). GP-EE decreases the mRNA levels of the inflammatory molecules studied. The molecules under study were as follows: inducible nitric oxide synthase (iNOS), tumor necrosis factor- $\alpha$ (TNF- $\alpha$ ), interleukin-1 $\beta$ (IL-1 $\beta$ ), the ionized calcium binding adaptor molecule-1(Iba-1) and the Toll like receptor-4 (TLR-4), as well as the iNOS protein level in LPS-stimulated microglia. Our findings suggest that, as a result of its ability to regulate excessive microglial activation, GP-EE possesses antiinflammatory properties. Therefore, acting as a chemopreventive agent, it may be of therapeutic interest in neurodegenerative diseases involving neuroinflammation. We can,
\end{abstract}

B. Rodríguez-Morgado · C. Santa-María • E. Revilla $\cdot$ J. Parrado

A. Castaño ( $\square)$

Departamento de Bioquímica y Biología Molecular, Universidad de

Sevillla, C/Profesor García González, 2, 41012 Sevilla, Spain

e-mail: angelica@us.es

B. Gordillo

Food Colour \& Quality Lab, Department of Nutrition \& Food

Science. Facultad de Farmacia, Universidad de Sevilla,

41012 Sevilla, Spain

M. Candiracci

Brigham and Women Hospital, Thorn 13, Anesthesia. 75 Francis St, Boston, MA 02115, USA therefore, propose GP-EE as a useful natural extract and one that would be beneficial to apply in the field of functional foods.

Keywords Grape pomace - Enzymatic extract · Polyphenols · Anti-inflammatory $\cdot$ Neurodegeneration

$\begin{array}{ll}\text { Abbreviations } \\ \text { GP } & \text { Grape pomace } \\ \text { GP-EE } & \text { Grape pomace enzymatic extract } \\ \text { LPS } & \text { Lipopolysaccharide } \\ \text { iNOS } & \text { Inducible nitric oxide synthase } \\ \text { TNF- } \alpha & \text { Tumor necrosis factor- alpha } \\ \text { IL-1 } \beta & \text { Interleukin-1 } \beta \\ \text { TLR-4 } & \text { Toll like receptor-4 } \\ \text { Iba-1 } & \text { Ionized calcium binding adaptor molecule-1 } \\ \text { UPLC } & \text { Ultra-high performance liquid chromatography } \\ \text { RT } & \text { Reverse transcription }\end{array}$

\section{Introduction}

Grape pomace, a winemaking industry by-product, has traditionally been considered as an environmental problem. However, GP is being increasingly recognized as a source of bioactive dietary compounds such as polyphenols [1]. To date, its efficient recovery to convert it into a high value-added product has been accomplished by conventional solid-liquid extraction with organic solvents (ethanol, methanol, ethyl ether, ethyl acetate, etc.) or by heated sulphurated water. It is also recovered enzymatically with carbohydrate hydrolases (cellulase and pectinase [1-5] and by physical methods such as superheated liquid extraction and supercritical fluid extraction. 
Grape polyphenols possess many biological activities, including anti-inflammatory properties [6] that can be beneficial to human health. It is now widely accepted that inflammation plays a pivotal role in neurodegenerative processes like Parkinson's disease or Alzheimer's disease. The hallmark of neuroinflammation is the activation of microglia, the brain's major defense against immune challenge. However, activated microglia may also contribute to neurodegeneration through the release of pro-inflammatory and/or cytotoxic factors such as IL- $1 \beta$, TNF- $\alpha$, nitric oxide (NO) and reactive oxygen intermediates, among others. It can therefore be assumed that a certain degree of brain inflammation is required to repair the damaged tissue yet excessive inflammation causes neuronal cell death. It would be interesting, therefore, to search for molecules that could help control inflammation in the CNS [7-10]. Natural polyphenols have been shown to exert neuroprotective properties by inhibiting the release of proinflammatory cytokines after LPS-activation of microglia [11-14].

This paper describes a new extraction method based on enzymatic technology for obtaining a valuable product from GP. The chemical and functional characterization of the enzymatic extract GP-EE, focusing on its anti-inflammatory properties, is also described.

\section{Materials and Methods}

\section{Enzymatic Hydrolysis}

GP was resuspended in water at a $20 \%$ concentration. Enzymatic hydrolysis was performed using an endoprotease mixture $(0,3 \% v / v)$ in a bioreactor using the $\mathrm{pH}$-stat method at $60{ }^{\circ} \mathrm{C}$ and $\mathrm{pH} 8$. The solids were then removed by filtration and the final product (GP-EE) was concentrated using a rotary evaporator, obtaining a completely water-soluble syrup. The concentrated extract was lyophilized to obtain a fine red powder with a phenolic yield of $12 \%$ of dry matter.

\section{GP-EE Chemical Composition}

The chemical composition of GP-EE, as protein, fat, carbohydrates and fiber, was characterized by using AOAC standard protocols [15]. Molecular-mass protein distribution in GP-EE was determined by size-exclusion chromatography using an ÄKTA-purifier (GE Healthcare) according to the procedure described by Bautista [16], using a Superdex Peptide ${ }^{\mathrm{TM}}$ 10/300 GL column (optimum separation range $0.1-7 \mathrm{kDa}$ ). Total phenolics were determined using a modification of the Folin-Ciocalteau method [17].

\section{Phenolic Composition by UPLC}

The analysis of the individual phenolics was undertaken via ultra-high performance liquid chromatography (UPLC) using Agilent 1260 system equipment with a diode-array detector. Phenols were separated on a $\mathrm{C} 18$ Poroshell 120 column ( $2.7 \mu \mathrm{m}$ particle size, $5 \mathrm{~cm} \times 4.6 \mathrm{~mm}$ ) (Agilent, Palo Alto, CA) and maintained at $25^{\circ} \mathrm{C}$. The solvents used were waterformic acid $(99: 1, v / v)$ as solvent $\mathrm{A}$, and acetonitrile as solvent B. The flow rate was $1.5 \mathrm{~mL} / \mathrm{min}$ and the injection volume was $30 \mu \mathrm{l}$. The linear gradient elution was: $0 \mathrm{~min}, 100 \% \mathrm{~A}$; $5 \mathrm{~min}, 95 \% \mathrm{~A}$ and $5 \% \mathrm{~B} ; 20 \mathrm{~min}, 50 \% \mathrm{~A}$ and $50 \% \mathrm{~B}$; $22 \mathrm{~min}, 100 \% \mathrm{~A} ; 25 \mathrm{~min}, 100 \% \mathrm{~A}$. The detection wavelengths were $280 \mathrm{~nm}$ (flavanols and benzoic acids); $320 \mathrm{~nm}$ (cinnamic acids and their derivates) and $370 \mathrm{~nm}$ (flavonols). The analyses were performed in triplicate for each sample.

Individual phenols were identified by comparing their retention time and spectra against standards. The external calibration method was used for quantification comparing the areas with standards of gallic, protocatechuic, caffeic acid, catechin, epicatechin, quercetin-3-O- glucoside and kaempferol-3-O-glucoside. All standards were HPLC-grade and purchased from Sigma-Aldrich (Madrid, Spain).

Phenolic compounds which were not available as standards were identified by their retention time and spectra, according to the literature. These compounds have been assayed by assuming that their molar absorptivity is the same as that of the corresponding free standard molecule.

\section{N13 Cell Culture and Immunostimulation Assays}

After stimulation with LPS, N13 microglia produces a repertoire of cytokines similar to primary microglia [18]. Cells were grown in RPMI 1640 (PAA, Linz, Austria) supplemented with $2 \mathrm{mM}$ glutamine (PAA), $5 \%(v / v)$ fetal bovine serum (PAA), $100 \mathrm{U} / \mathrm{mL} 131$ penicillin, and $100 \mu \mathrm{g} / \mathrm{mL}$ streptomycin (PAA) at $37{ }^{\circ} \mathrm{C}$ and $5 \% \mathrm{CO}_{2}$. For subculture, cells were removed from the culture flask with a scraper, resuspended in the culture medium, and subcultured in 6-well plates for experiments (Nunc, Thermo Fisher Scientific, USA) in culture medium at a density of $5.0 \times 10^{5}$ cells $/$ well $/ 2 \mathrm{~mL}$. After adhering, cells were stimulated with LPS $(0.01 \mu \mathrm{g} / \mathrm{mL})$ and simultaneously different concentrations of GP-EE were added $(0,1,5$ and $10 \mu \mathrm{g} / \mathrm{mL}$ of polyphenols). Finally, they were collected at different times after stimulation (1, 4 and $6 \mathrm{~h}$ ), to extract RNA and proteins. Cells treated only with cell culture media but no GP-EE or LPS were used as control.

\section{Determination of Cell Viability}

After $24 \mathrm{~h}$ of GP-EE treatment $(0,1,5$ and $10 \mu \mathrm{g} / \mathrm{mL}$ of polyphenols), cells were washed with $1 \mathrm{~mL}$ of PBS and stained for $60 \mathrm{~min}$ with $1 \mathrm{~mL}$ of a $1 \%$ crystal violet solution. 
After careful aspiration of the crystal violet solution, the plates were washed with deionized water and dried prior to the solubilization of the bound dye with $1 \mathrm{~mL}$ of a $1 \%$ aqueous SDS solution. The optical density of the plates was measured at $590 \mathrm{~nm}$ in a microplate spectrophotometer.

\section{RNA Extraction and Reverse Transcription}

For PCR analysis, total RNA was extracted from collected cells using the Tripure ${ }^{\mathrm{TM}}$ Isolation Reagent (Roche, Germany), following the manufacturer's instructions. This procedure allows the isolation of total RNA, DNA and protein fractions from a single sample. Reverse transcription (RT) was performed using random hexamers primers, $3 \mu \mathrm{g}$ of total RNA as a template and the High-Capacity cDNA Archive Kit (Applied Biosystems) following the manufacturer's recommendations as previously described [19].

\section{Real-Time PCR}

After RT, the cDNA was diluted in sterile water and used as template for amplification by the polymerase chain reaction. For real time RT-PCR, each specific gene product was amplified using commercial TaqMan ${ }^{\mathrm{TM}}$ probes employing the ABI Prism 7000 sequence detector (Applied Biosystems, Madrid, Spain) as previously described [18]. The cDNA levels were determined using GAPDH as housekeeper. Threshold cycle (Ct) values were calculated using the software supplied by Applied Biosystems.

\section{Immunoblot}

Protein pellets obtained using the Tripure $^{\mathrm{TM}}$ isolation reagent were resuspended in $4 \%$ SDS and $8 \mathrm{M}$ urea in $40 \mathrm{mM}$ Tris$\mathrm{HCl}$. The total recovery and integrity of these fractions were determined by Lowry et al. [20] and SDS-polyacrylamide gel electrophoresis. Immunoblots were performed [21]. Membranes were incubated overnight at $4{ }^{\circ} \mathrm{C}$ with the rabbit polyclonal antibody antiinOS (BD Bioscience, USA, 1/1000) or the mouse monoclonal antibody against $\beta$-actin (SigmaAldrich) at a dilution of $1 / 10,000$. The blots were developed using the ECL-plus detection method (Amersham).

For quantification, the optical density of the individual bands was analysed using PCBAS 2.08 software (Raytest Inc, Berlin, Germany) and the optical density of each band was normalized relative to the optical density of $\beta$-actin.

\section{Statistics}

Data were expressed individually, as mean $\pm \mathrm{SD}$ or as a percentage with respect to control.
At least three independent experiments were conducted and analyzed statistically using $t$-student Bonferroni or analysis. Different levels of significance $\left({ }^{*} p<0.05\right.$ and $\left.{ }^{* *} p<0.001\right)$ are considered statistically significant.

\section{Results and Discussion}

\section{Obtaining the Grape Pomace Enzymatic Extract (GP-EE)}

GP is a water-insoluble solid by-product composed mainly of fiber (54\%) and minor components such as fat (7\%), proteins (9\%) and soluble carbohydrates (14\%). We have developed a new process using proteases in order to extract and solubilize valuable compounds such as peptides, polyphenols, etc. In this process, the strategy consisted of breaking down cell structure, thus solubilizing the protein. This led to the release of molecules such as phenolics or peptides. Enzymatic extraction processes using carbohydrate hydrolase (cellulase and pectinase) enzymes have been described previously [2, 22], but not the use of proteases. Therefore not only have we tried to recover phenolics but also other functional biomolecules with anti-inflammatory and antioxidant capacities such as peptides. The other enzymatic processes hydrolyzed structural carbohydrates, focusing mainly on the recovery of phenols. Due to the fact that the stability of the active ingredients is enhanced at low temperatures and pressures, the biological extraction process employing hydrolytic enzymes has certain advantages over classical chemical extraction processes. The enzymatic extraction method excludes the use of xenobiotics or toxic reagents, something that must also be taken into account, as it is more environmentally friendly.

Due to their fiber compounds (cellulose, hemicellulose, pectin and lignine) carbohydrates, which are the main component in GP-EE (47\%), are not extracted by the enzymatic treatment and remain insoluble and are separated from GP-EE by centrifugation. The second main compound in GP-EE is protein $(14 \%)$ which is present in a greater amount than in GP. This is due to the use of proteases which extract, solubilize and hydrolyse the initial insoluble proteins. The physical properties of the proteins in GP-EE are somewhat different to those of GP proteins, as shown in Fig. 1. In GP-EE, the proteins are mainly in the form of peptides and free amino acids. This change in the protein size modifies drastically water solubility, thus the components of GP-EE are completely soluble, independent of the $\mathrm{pH}$. This results in an increase in nutritional functionality. Phenols (12\%), that have been concentrated due to the enzymatic process, are the third component. Although the amount of polyphenols in the GP-EE is similar to that found by other studies [2], our target was not only to obtain a phenolic extract but also one that contains polyphenols and other bioactive molecules such as peptides, carbohydrates and lipids in a soluble form. 
Fig. 1 Size-exclusion chromatography and molecular weight distribution of GP-EE

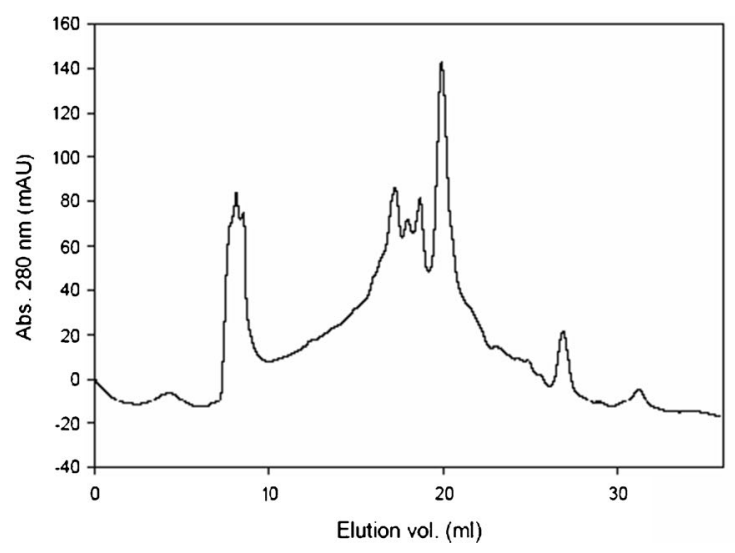

\begin{tabular}{|c|r|}
\hline $\begin{array}{c}\text { Molecular } \\
\text { weight } \\
\text { (Daltons) }\end{array}$ & GP-EE \\
\hline$>10.000$ & 12.1 \\
\hline $\mathbf{1 0 . 0 0 0 - 5 . 0 0 0}$ & 4.3 \\
\hline $\mathbf{5 . 0 0 0 - 1 . 0 0 0}$ & 12.9 \\
\hline $\mathbf{1 . 0 0 0 - 3 0 0}$ & 22.1 \\
\hline$<\mathbf{3 0 0}$ & 48.6 \\
\hline
\end{tabular}

Finally, the fat content is greatly reduced but it is solubilized due to protein interactions. A similar process of lipid extraction and solubilization (emulsion) by proteases from a natural organic matter has also been described [23].

The next goal was to analyze the presence of bioactive compounds that may be involved in the beneficial activities of GP-EE. Using bibliographical data, we have devised a series of bioactive compounds with anti-inflammatory, antitumoral and antioxidant properties that are present in grape seeds and skin, such as catechin, epicathechin, gallocatechin, kaempferol, procyanidin B1, procyanidin B2, quercetin and resveratrol. Although a similar grape pomace enzymatic extract has been already characterized [24], we have performed an in-depth characterization of the polyphenolic and protein profile of our GP-EE. Interestingly, present results suggest that the enzymatic extract of grape pomace (GP-EE) comprises a rich source of bioactive non-colored polyphenols (12\%), comprising mainly flavonoids (flavanols and flavonols) and phenolic acids.

Flavonoids are important for human health because of their high levels of pharmacological activity as radical scavengers
[25]. Three flavanols, six flavonols and four phenolic acids were identified and quantified by UPLC (Table 1). Among the flavanols detected, epicatechin and catechin were the most abundant compounds ( 35.7 and $33.7 \mathrm{mg} / 100 \mathrm{~g}$, respectively), while procyanidin $\mathrm{B} 1$ was also present in high amounts $(21.6 \mathrm{mg} / 100 \mathrm{~g})$. The main flavonols were quercetin 3-Oglucoside, kaempferol 3-O-glucoside and quercetin 3- $O$ rutinoside $(50.9,21.9$ and $20.5 \mathrm{mg} / 100 \mathrm{~g}$, respectively). Although in lower amounts, three $O$-glycosides from the aglycones quercetin and kaempferol were also found in the enzymatic extract.

With respect to the phenolic acids, both hydroxybenzoic (gallic and protocatechuic) and hydroxycinammic (caffeic and caftaric) acids were detected in extracts. Protocatechuic acid was the most abundant phenolic acid $(27.1 \mathrm{mg} / 100 \mathrm{~g})$, although the other phenolic acids were also detected in considerable quantities.

Therefore, polyphenols, including both hydrophobic and hidrophylic groups that interact with proteins and polysacharides on the cell wall, can be released after treatment with proteases.
Table 1 Detailed phenolic composition and total phenolic content of GP-EE (mg/100 g DW)

\begin{tabular}{lllc}
\hline Compound & Phenolic family & $\lambda(\mathrm{nm})$ & Concentration $(\mathrm{mg} / 100 \mathrm{~g})$ \\
\hline Gallic acid & Phenolic acid & 280 & $9.43 \pm 0.42$ \\
Caffeic acid & Phenolic acid & 320 & $9.69 \pm 0.10$ \\
Caftaric acid & Phenolic acid & 320 & $16.32 \pm 0.13$ \\
Protocatechuic acid & Phenolic acid & 280 & $27.07 \pm 0.71$ \\
Catechin & Flavanol & 280 & $33.74 \pm 0.81$ \\
Epicatechin & Flavanol & 280 & $35.66 \pm 0.59$ \\
Procyanidin B1 & Flavanol & 280 & $21.62 \pm 0.43$ \\
Quercetin-3-O-rutinoside (rutin) & Flavonol & 370 & $20.53 \pm 0.43$ \\
Quercetin-3-O-glucoside & Flavonol & 370 & $50.92 \pm 0.04$ \\
Kaempferol-3- $O$-glucoside & Flavonol & 370 & $21.92 \pm 0.12$ \\
Quercetin 3-O-galactoside & Flavonol & 370 & $6.42 \pm 0.31$ \\
Kaempferol 3- $O$-galactoside & Flavonol & 370 & $10.05 \pm 0.31$ \\
Kaempferol 3- $O$-glucuronide & Flavonol & 370 & $5.82 \pm 0.18$ \\
Total phenols (mg/g) & & 765 & $12800.13 \pm 870$
\end{tabular}


Anti-inflammatory Activity of GP-EE on LPS-activated N13 Cells

The anti-inflammatory property was analysed by in vitro assays on N13 cells stimulated with LPS and then treated with different concentrations of GP-EE. It is known that N13 microglia produces a repertoire of cytokines similar to primary microglia [18] after stimulation with the classical proinflammatory agent LPS. Accordingly, present results show up-regulation of mRNA expression of pro-inflammatory molecules in N13 microglia at the time points studied (1, 4 and $6 \mathrm{~h}$ ) after LPS-stimulation. Molecules tested were the cytokines TNF- $\alpha$, IL-1 $\beta$; the inflammatory enzyme iNOS; the receptor TLR-4 as well as the molecule iba-1. Specifically, mRNA values reached a maximum at hour 1 for TNF- $\alpha$ and TLR-4; hour 4 for IL-1 $\beta$, and at hour 6 for iNOS and Iba-1.
To assay whether GP-EE exerts any protective effect on LPSstimulated cells, N13 cells were simultaneously treated with LPS and different concentrations of GP-EE $(0,1,5$ and $10 \mu \mathrm{g} /$ $\mathrm{mL}$ on polyphenols). No cytotoxicity was observed for GPEE treatments at the tested concentrations (data not shown), as tested by cell viability assay. Similarly, GP-EE did not upregulate the mRNA expression of pro-inflammatory factors when it was added to control cells not stimulated with LPS (data not shown).

Interestingly, GP-EE decreased the up-regulation of the mRNA of all the pro-inflammatory factors studied (TNF- $\alpha$, TLR-4, IL-1 $\beta$, iba-1 and iNOS, ) after LPS- stimulation in a dose-dependent manner (Fig. 2). In the presence of GP-EE the expression of TNF- $\alpha$ mRNA was strongly inhibited, showing a significant decrease (50\% with respect to LPS-treated cells) with a medium concentration of GP-EE $(5 \mu \mathrm{g} / \mathrm{mL}$ on
Fig. 2 The protective effect of GP-EE on the expression of mRNA of: TNF- $\alpha$ (a), TLR-4 (b), IL-1 $\beta$ (c), Iba-1 (d) and iNOS (e) in N13 microglia cells. N13 cells activated with LPS $(1 \mu \mathrm{g} / \mathrm{mL})$ were treated with different concentrations of GPEE. All data are presented as mean \pm S.D of three independent experiments. Bonferroni analysis was employed to compared the differences between the experimental groups: $* p<0.05$, $* * p<0.01$ and $* * * p<0.001$ compared with control with LPS alone; ${ }^{*} p<0.05$ compared with $1 \mu \mathrm{g} / \mathrm{ml} \mathrm{GP}$-EE and $\& \& \& p<0.001$ compared with $5 \mu \mathrm{g} / \mathrm{ml}$ GP-EE a

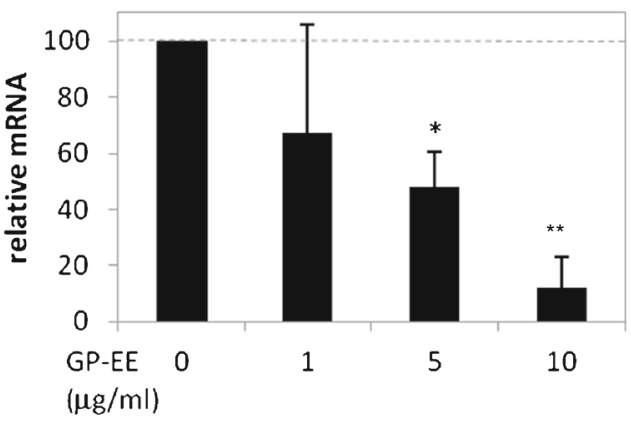

c

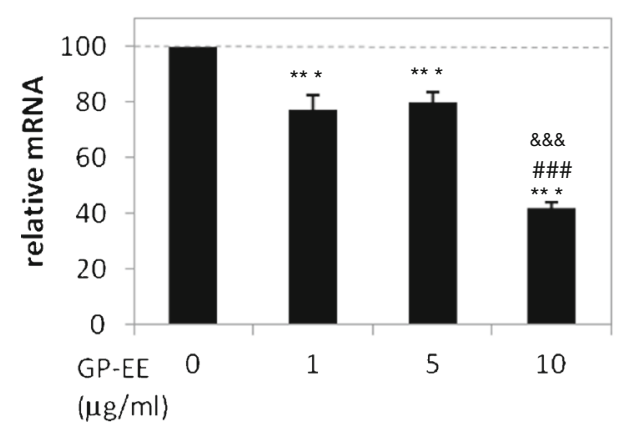

e

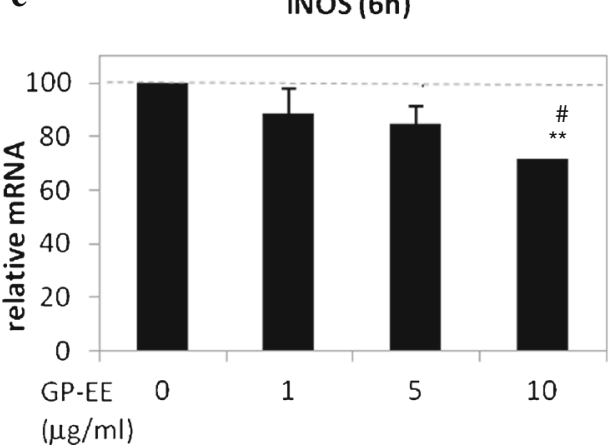

b

TLR4 (1h)

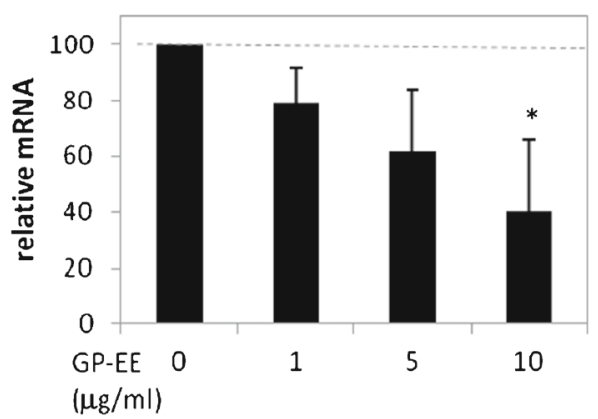

d

Iba1 (6h)

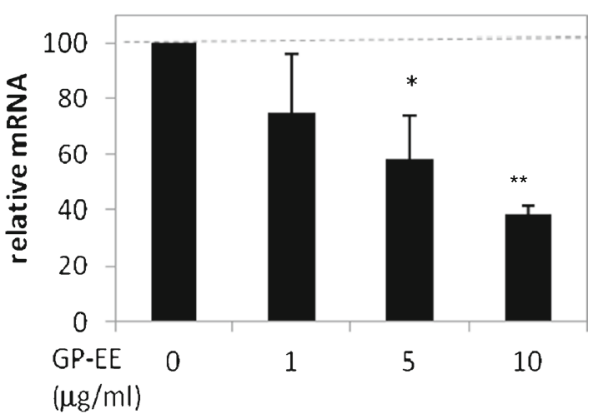


polyphenols) and an even higher decrease (90\% with respect to LPS-stimulated cells; $p<0.05$; Fig. 2a) using the highest concentration of GP-EE tested $(10 \mu \mathrm{g} / \mathrm{mL}$ on polyphenols).

TLR-4 is the central component of the LPS receptor [26]. Our results show that TLR-4 mRNA also increased after LPSstimulation. Simultaneous treatment with the highest concentration of GP-EE $(10 \mu \mathrm{g} / \mathrm{mL})$ significantly decreased TLR-4 mRNA to a value of $40.63 \%$ with respect to LPS-treated cells $(p<0.05$; Fig. $2 \mathrm{~b})$, thus also interfering in the expression of the LPS-receptor.

The expression of IL- $\beta$ mRNA was also significantly inhibited in presence of GP-EE and the decrease was also dose-dependent. There was a decrease of up to $42 \%$ with respect to LPS cells stimulated with the highest concentration of GP-EE ( $10 \mu \mathrm{g} / \mathrm{mL}$ on polyphenols; $p<0.001$; Fig. $2 \mathrm{c}$ ).

Iba-1 is a microglia/macrophage-specific calcium-binding protein that participates in membrane ruffling and phagocytosis in activated microglia [27]. Accordingly, the activation of Iba-1 mRNA expression was observed after LPS-stimulation (Fig. 2d). Iba-1 mRNA values also decreased with GP-EE with respect to LPS-treated cells, being statistically significant at concentrations corresponding to $5 \mu \mathrm{g} / \mathrm{mL}$ and $10 \mu \mathrm{g} / \mathrm{mL}$ of polyphenols (75 and $38 \%$ with respect to LPS-stimulated cells; $p<0.05$ ).

Finally, we tested the pro-inflammatory enzyme iNOS. GPEE also decreases the upregulation of iNOS mRNA after the LPS-stimulation of N13, but the effect was less pronounced than that described above, reaching values of up to $84.6 \%$ $(p<0.05)$ and $72 \%(p<0.001)$ with regard to that of LPSstimulated culture (Fig. 2e) at GP-EE concentrations of 5 and $10 \mu \mathrm{g} / \mathrm{mL}$ of polyphenols respectively. Interestingly, analysis of protein isolated from LPS-stimulated N13 cells also confirmed a decrease in iNOS protein expressions on LPSstimulation when compared with cells treated with GP-EE. Our results (Fig. 3) show an approximately $40 \%$ inhibition of iNOS protein by GP-EE at doses of 5 and $10 \mu \mathrm{g} / \mathrm{mL}$ polyphenols $(p<0.05)$.

In conclusion, GP-EE exerts a clear anti-inflammatory effect in vitro, decreasing all of the pro-inflammatory factors

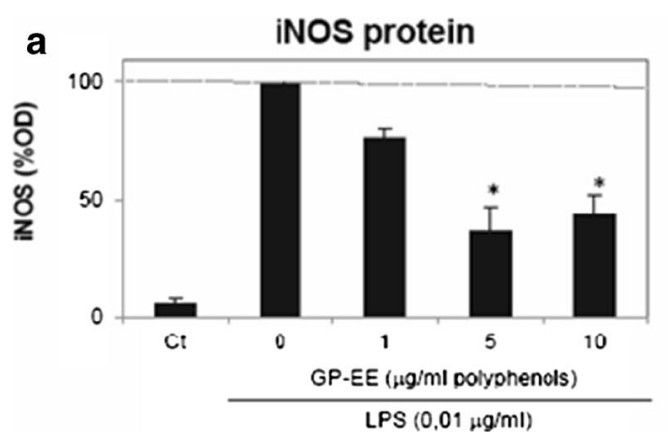

Fig. 3 Inhibitory effect of GP-EE on the expression of the iNOS protein in LPS-stimulated N13 cells. Bands were scanned and the relative density of iNOS (iNOS/ $\beta$-actin) was calculated (a). Results are mean \pm SD of that characterize microglial activation. These results coincide or agree with those of other research groups. Indeed, a similar finding has recently been reported and thus nature molecules such as flavonoids and tocopherols inhibit the release of proinflammatory cytokines after activating microglia with LPS [11-13].

Catechin is one of the most abundant flavanols in GP-EE. It has been reported that catechin isolated from Juniperus rigida effectively inhibits LPS-induced NO production in RAW264.7 macrophage cells [28]. We can, therefore, suggest that the anti-inflammatory properties of GP-EE make it an ideal source of ingredients to be used as a preventive for neurodegenerative processes. In this regard, wine consumption has been reported as potentially protecting against certain neurological disorders and that its neuroprotective activity is related to its polyphenolic content [29]. However, we must not overlook the fact that other components of GP-EE may also contribute to its anti-inflammatory properties. In fact, the second main component in GP-EE is protein (14\%), mainly in the form of peptides and free amino acids and it is known that vegetable peptides, such as the lunasin from soybean, exert anti-oxidant and anti-inflammatory properties [30].

Neuroinflammation is an important contributor to the pathogenesis of neurodegenerative disorders such as Alzheimer's or Parkinson's disease, both of which present an increasing health problem in modern society [7-10]. One of the hallmarks of neurodegeneration is the presence of activated microglia, the resident macrophages in the central nervous system, and the first line of defense after tissue damage and/or infection. However, activated microglia may also contribute to neurodegeneration through the release of pro-inflammatory and/or cytotoxic factors such as IL $-1 \beta, \mathrm{TNF}-\alpha, \mathrm{NO}$ and reactive oxygen intermediates among others. Therefore, after an initial insult microglia activation damages neurons that then release toxic soluble factors. These in turn induce microglial activation, termed as reactive microgliosis. Thus, a self-perpetuating cycle causing prolonged inflammation is created $[7,8]$. In this context it has been proposed that regulating excessive microglial activation may be therapeutic in

b

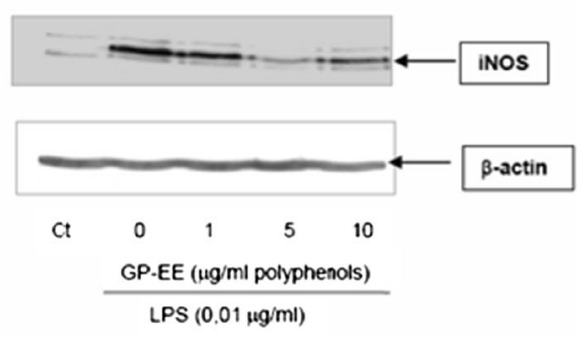

three different experiments. T-student analysis was employed ( $p<0.05$ vs control). The lower panel shows a representative immunoblot in which iNOS is detected (b) 
neurodegenerative diseases [31]. Therefore, we can suggest that the anti-inflammatory properties of GP-EE make it an ideal source of ingredients to be used as chemopreventive agents in neurodegenerative disorders linked to neuroinflammation such as Alzheimer's or Parkinson's disease - a growing health concern in modern societies [7-10].

The potential use of polyphenols for the prevention/ treatment of neurological disorders is largely hindered by their complexity and also by the limited knowledge regarding their bioavailability, metabolism, and bioactivity, especially in the brain. However, Wang et al. [32] have recently demonstrated that after dietary supplementation with polyphenolic preparations from grape, bioactive polyphenol metabolites selectively reach and accumulate in the brain. In a mouse model of Alzheimer's disease, these polyphenolic preparations significantly mitigate amyloid-(A $\beta)$ mediated neuropathology and cognitive impairments.

In conclusion, we have developed a biological extraction process that allows grape pomace to be extracted with several advantages such as high stability and high content of bioactive compounds such as polyphenols and peptides, while avoiding the use of of xenobiotics or toxic reagents. The results strongly support that this extract possesses anti-inflammatory properties that have been widely linked to polyphenols. As a result, GP-EE may be of therapeutic interest in neurodegenerative diseases linked to neuroinflammation by acting as a chemopreventive agent. Thus, we propose the use of GP-EE as a natural extract whose implementation in the functional food field could provide health benefits.

Acknowledgments This research was supported by a grant of the Ministerio de Innovación y Ciencia, Spain (TRACE 2009-0263-01).

Conflict of Interest The authors declare no conflicting interests or financial disclosures.

\section{References}

1. Rubilar M, Pinelo M, Shene C, Sineiro J, Núñez MJ (2007) Separation and HPLC-MS identification of phenolic antioxidants from agricultural residues: almond hulls and grape pomace. J Agric Food Chem 55:10101-10109

2. Ariel L, Fontana R, Antoniolli A, Bottini R (2013) Grape pomace as a sustainable source of bioactive compounds: extraction, characterization, and biotechnological applications of phenolics. J Agric Food Chem 61:8987-9003

3. Luque-Rodríguez JM, Pérez-Juan P, Luque de Castro MD (2006) Extraction of polyphenols from vine shoots of Vitis vinifera by superheated ethanol-water mixtures. J Agric Food Chem 54:87758781
4. Monagas M, Hernández-Ledesma B, Gómez-Cordovés C, Bartolomé B (2006) Commercial dietary ingredients from Vitis vinifera $\mathrm{L}$. leaves and grape skins: antioxidant and chemical characterization. J Agric Food Chem 54:319-327

5. Kashif Ghafoor K, AL-Juhaimi FY, Choi YE (2012) Supercritical fluid extraction of phenolic compounds and antioxidants from grape (Vitis labrusca B.) seeds. Plant Foods Hum Nutr 67:407-414

6. Xia EQ, Deng GF, Guo YJ, Li HB (2010) Biological activities of polyphenols from grapes. Int J Mol Sci 11:622-646

7. McGeer PL, McGeer EG (2004) Inflammation and the degenerative diseases of aging. Ann N Y Acad Sci 1035:104-116

8. Gao HM, Hong JS (2008) Why neurodegenerative diseases are progressive: uncontrolled inflammation drives disease progression. Trends Immunol 29:357-365

9. Block ML, Zecca L, Hong JS (2007) Microglia-mediated neurotoxicity: uncovering the molecular mechanisms. Nat Rev Neurosci 8: 57-69

10. Lull ME, Block ML (2010) Microglial activation and chronic neurodegeneration. Neurotherapeutics 7:354-365

11. Candiracci M, Piatti E, Dominguez-Barragán M, García-Antrás D, Morgado B, Ruano D, Gutiérrez JF, Parrado J, Castaño A (2012) Anti-inflammatory activity of a honey flavonoid extract on lipopolysaccharide-activated N13 microglial cells. J Agric Food Chem 60(50):12304-12311

12. Bi XL, Yang J, Dong YX, Wang JM, Cui YH, Ikeshima T, Zhao YQ, Wu CF (2005) Resveratrol inhibits nitric oxide and TNF-alpha production by lipopolysaccharide-activated microglia. Int Immunopharmacol 5:185-193

13. Lu X, Ma L, Ruan L, Kong Y, Mou H, Zhang Z, Wang Z, Wang JM, Le Y (2010) Resveratrol differentially modulates inflammatory responses of microglia and astrocytes. J Neuroinflammation 7:46-60

14. Ha SK, Moon E, Kim S (2010) Chrysin suppresses LPS-stimulated proinflammatory responses by blocking NF- $\mathrm{KB}$ and JNK activations in microglia cells. Neurosci Lett 485:143-147

15. AOAC (1990) Official methods of analysis, 14th edn. DC. Association of Official Analytical Chemists, Washington

16. Bautista J, Hernandez-Pinzón I, Alaiz M, Parrado J, Millan F (1996) Low molecular weight sunflower protein hydrolysate with low concentration in aromatic acids. J Agric Food Chem 44:967-971

17. Singleton VL, Rossi JA Jr (1965) Colorimetry of total phenolics with phosphomolybdic-phosphotungstic acid reagents. Am J Enol Vitic 16:144-158

18. Righi M, Mori L, De Libero G, Sironi M, Biondi A, Mantovani A, Donini SD, Ricciardi-Castagnoli P (1989) Monokine production by microglial cell clones. Eur J Immunol 19:1443-1448

19. Gavilán MP, Castaño A, Torres M, Revilla E, Caballero C, Jiménez S, García-Martínez A, Parrado J, Vitorica J, Ruano D (2009) Agerelated increase in the immunoproteasome content in rat hippocampus: molecular and functional aspects. J Neurochem 108:260-270

20. Lowry OH, Rosebrough NJ, Farr AL, Randall RJ (1951) Protein measurement with the folin phenol reagent. J Biol Chem 193:265-275

21. Ruano D, Revilla E, Gavilán MP, Vizuete ML, Pintado C, Vitorica J, Castaño A (2006) Role of p38 and iNOS in the in vivo dopaminergic cells degeneration induced by inflammatory processes after LPS injection. Neuroscience 140:1157-1168

22. Kammerer D, Aus A, Schieber A, Carle R (2005) A novel process for the recovery of polyphenols from grape (Vitis vinifera $\mathrm{L}$ ) pomace. J Food Sci 70:157-163

23. Gbogouri GA, Linder M, Fanni J, Parmentier M (2006) Analysis of lipids extracted from salmon (Salmo salar) heads by commercial proteolytic enzymes. Eur J Lipid Sci Technol 108:766-775

24. Rodriguez-Rodriguez R, Justo ML, Claro CM, Vila E, Parrado J, Herrera MD, Alvarez de Sotomayor M (2012) Endotheliumdependent vasodilator and antioxidant properties of a novel enzymatic extract of grape pomace from wine industrial waste. Food Chem 135:1044-1051 
25. Yao H, Jiang YM, Shi J, Tomás-Barberán FA, Datta N, Singanusong R, Chen SS (2004) Flavonoids in food and their health benefits. Plant Foods Hum Nutr 59:113-122

26. Beutler B (2002) TLR-4 as the mammalian endotoxin sensor. Curr Top Microbiol Immunol 270:109-120

27. Ito D, Tanaka K, Suzuki S, Dembo T, Fukuuchi Y (2001) Enhanced expression of Iba-1, ionized calcium-binding adapter molecule-1, after transient focal cerebral ischemia in rat brain. Stroke 32:1208-1215

28. Jeong EJ, Seo H, Yang H, Kim J, Sung SH, Kim YC (2012) Antiinflammatory phenolics isolated from Juniperus rigida leaves and twigs in lipopolysaccharide-stimulated RAW264.7 macrophage cells. J Enzym Inhib Med Chem 27:875-879

29. Gómez-Serranillos MP, Martín S, Ortega T, Palomino OM, Prodanov M, Vacas V, Hernández T, Estrella I, Carretero ME (2009) Study of red wine neuroprotection on astrocytes. Plant Foods Hum Nutr 64: $238-243$

30. Hernández-Ledesma B, Hsieh CC, de Lumen BO (2013) Chemopreventive properties of Peptide Lunasin: a review. Protein Pept Lett 20(4):424-432

31. Ransohoff RM, Perry VH (2009) Microglial physiology: unique stimuli, specialized responses. Annu Rev Immunol 27:119-145

32. Wang J, Weina B, Chen A, Freire D, Vempati P, Zhao W, Gong B, Janle EM, Chen T-Y, Ferruzzi MG, Schmeidler J, Ho L, Pasinetti GMJ (2014) Targeting multiple pathogenic mechanisms with polyphenols for the treatment of Alzheimer's disease experimental approach and therapeutic implications. Front Aging Neurosci 6:42. doi: 10.3389/fnagi.2014.00042 